OPEN ACCESS

Edited by:

Andre Lacroix

Université de Montréal, Canada

Reviewed by:

Tullio Florio,

University of Genoa, Italy

Rafael Vazquez-Martinez,

University of Córdoba, Spain

${ }^{*}$ Correspondence:

Maria Candida Barisson

Villares Fragoso

maria.villares@hc.fm.usp.br

Specialty section:

This article was submitted to Neuroendocrine Science,

a section of the journa

Frontiers in Endocrinology

Received: 03 May 2016

Accepted: 12 July 2016

Published: 27 July 2016

Citation:

Villares Fragoso MCB,

Wanichi IQ, Cavalcante IP and Mariani BMP (2016) The Role of gsp Mutations on the Development of Adrenocortical Tumors and

Adrenal Hyperplasia.

Front. Endocrinol. 7:104.

doi: 10.3389/fendo.2016.00104

\section{The Role of gsp Mutations on the Development of Adrenocortical Tumors and Adrenal Hyperplasia}

\author{
Maria Candida Barisson Villares Fragoso*, Ingrid Quevedo Wanichi, \\ Isadora Pontes Cavalcante and Beatriz Marinho de Paula Mariani \\ Unidade de Suprarrenal, Disciplina de Endocrinologia e Metabologia, Laboratorio de Hormonios e Genetica Molecular \\ LIM/42, Hospital das Clinicas, Faculdade de Medicina da Universidade de Sao Paulo, Sao Paulo, Brazil
}

Somatic GNAS point mutations, commonly known as gsp mutations, are involved in the pathogenesis of McCune-Albright syndrome (MAS) and have also been described in autonomous hormone-producing tumors, such as somatotropinoma, corticotrophoma, thyroid cancer, ovarian and testicular Leydig cell tumors, and primary macronodular adrenocortical hyperplasia (PMAH) (1-3). The involvement of gsp mutations in adrenal tumors was first described by Lyons et al. Since then, several studies have detected the presence of gsp mutations in adrenal tumors, but none of them could explain its presence along or the mechanism that leads to tumor formation and hormone hypersecretion. As a result, the molecular pathogenesis of the majority of sporadic adrenocortical tumors remains unclear (3). PMAH has also been reported with gsp somatic mutations in a few cases. Fragoso et al. identified two distinct gsp somatic mutations affecting arginine residues on codon 201 of GNAS in a few patients with PMAH who lacked any features or manifestations of MAS. Followed by this discovery, other studies have continued looking for gsp mutations based on strong prior evidence demonstrating that increased cAMP signaling is sufficient for cell proliferation and cortisol production (2, 4). With consideration for the previously reported findings, we conjecture that although somatic activating mutations in GNAS are a rare molecular event, these mutations could probably be sufficient to induce the development of macronodule hyperplasia and variable cortisol secretion. In this manuscript, we revised the presence of gsp mutations associated with adrenal cortical tumors and hyperplasia.

Keywords: gsp, GNAS, adrenal, tumors, hyperplasia, mutations

\section{INTRODUCTION}

Heterotrimeric $\mathrm{G}$ proteins are the molecular switches that turn on intracellular signaling cascades in response to the activation of G protein-coupled receptors (GPCRs) by extracellular stimuli. Therefore, $G$ proteins play a crucial role in defining the specificity and temporal characteristics of the cellular response. Heterotrimeric $\mathrm{G}$ proteins consist of three subunits, $\alpha, \beta$, and $\gamma$, and their switching function depends on the ability of the G protein $\alpha$-subunit $(\mathrm{G} \alpha)$ to cycle between an inactive GDP-bound conformation that is primed to interact with an activated receptor and an active GTP-bound conformation that can modulate the activity of downstream effector proteins. The $\alpha$ subunit is a GTPase; therefore, when the receptor stimulates the G protein, this subunit releases GDP 
and binds GTP. In this activated state, several $\alpha$ subunit types act directly on effector molecules to modulate their activity. Some $\alpha$ subunits show specificity for effectors; for example, $\alpha$ s activates adenylate cyclases, $\alpha$ inhibits adenylate cyclases, and $\alpha q$ activates phospholipase C isozymes (5) (Figure 1).

The gene encoding the alpha subunit of stimulatory $G$ proteins (GNAS, OMIM 139320) is located on chromosome 20q13.32 (6). Activating somatic mutations of stimulatory $\mathrm{G}$ protein called $g s p$ mutations can result in the loss of intrinsic GTPase activity of the $\alpha$ subunit with subsequent constitutive activation of adenylate cyclase $(7,8)$.

gsp mutations are involved in the pathogenesis of McCuneAlbright syndrome (MAS), which is an endocrine disorder that is classically defined by the clinical triad of bone fibrous dysplasia, café-au-lait skin, and peripheral precocious puberty (1).

Patients with MAS present with a postzygotic gsp mutation in a mosaic distribution, resulting in varying degrees of tissue involvement that range from a single site to a widespread distribution. However, if these mutations were germline, they would be lethal. To date, this concept is supported by the absence of any cases resulting from vertical transmission and the discordance in disease among monozygotic twins (9). Adrenal hypercortisolism affects a minority of patients with MAS due to adrenal nodular hyperplasia and around 20 cases were described (8).
Naturally occurring mutations in codons 201 and 227, which alter the GTPase activity in the GNAS gene, have been described in autonomous hormone-producing tumors. Mutations involving substitution of either cysteine or histidine and, more rarely, serine for arginine at codon 201 or arginine for glutamine at codon 227 were first described in $\mathrm{GH}$-producing pituitary tumors (10).

The $g s p$ mutations have also been described in several tumors, such as somatotropinoma, thyroid tumor, ovarian and testicular Leydig cell tumors, and primary macronodular adrenocortical hyperplasia (PMAH), as well as in rare cases of corticotropinoma, cortisol, and aldosterone-secreting adrenocortical adenoma. All cases described were outside of the classical presentation of MAS $(1,2,4,7)$.

\section{cAMP/PKA Signaling in Adrenocortical Cells}

The discovery of the role of cAMP (adenosine $3^{\prime} 5^{\prime}$-cyclic monophosphate) as an intracellular mediator introduced the concept of second messengers in signal transduction. cAMP is a nucleotide synthesized within cells using ATP, and it is under the action of a membrane-bound enzyme, adenylate cyclase. cAMP is continuously produced and inactivated by hydrolysis

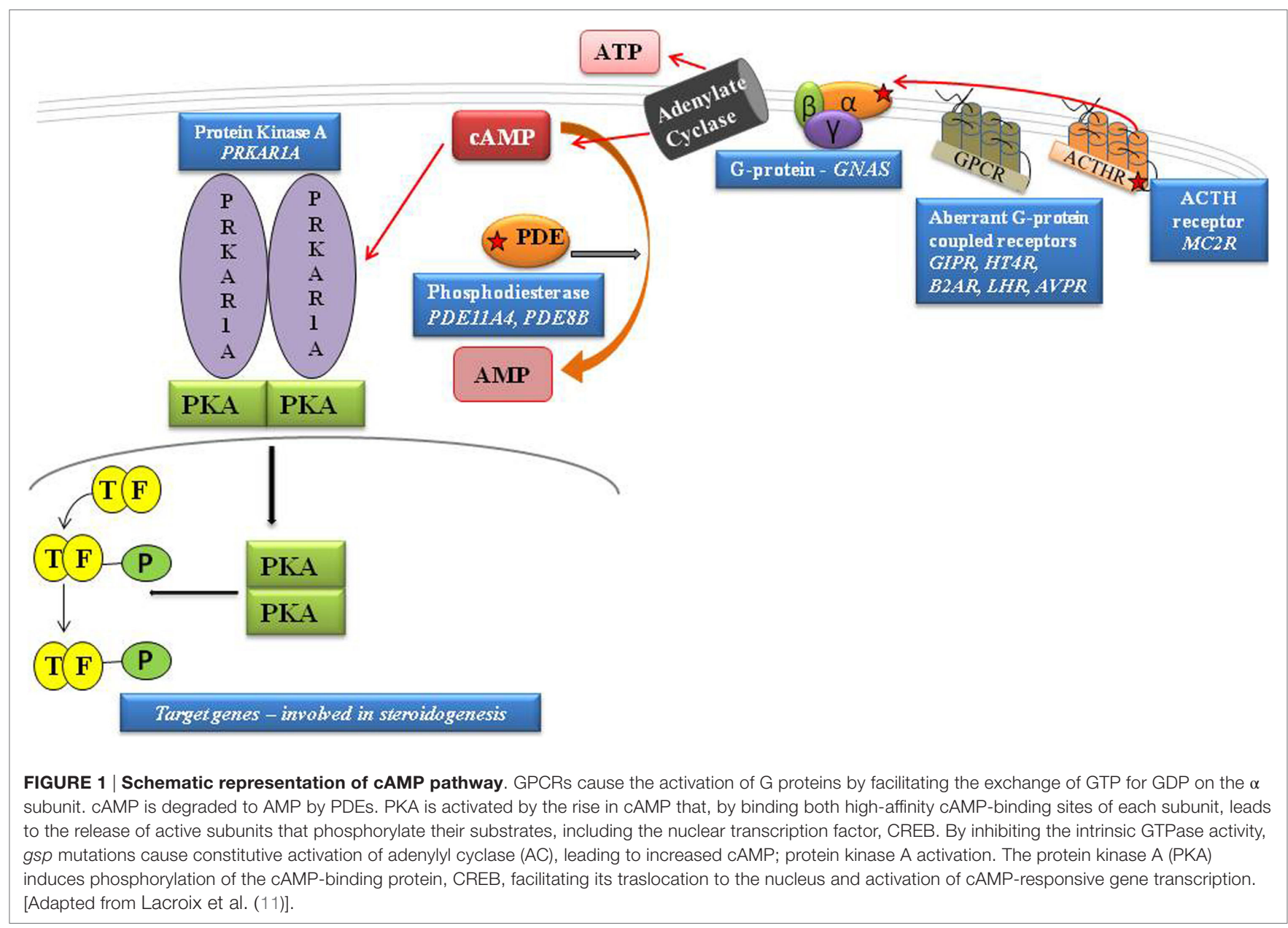


of $5^{\prime}$-AMP through a family of enzymes known as phosphodiesterase (12-14).

cAMP regulates many aspects of cell function, including enzymes involved in energy metabolism, cell division and differentiation, ion transport, ion channels, and contractile proteins. However, these effects are produced by a common mechanism, the activation of protein kinases by cAMP (Figure 2).

Proteins are phosphorylated by various protein kinases. The substrates of protein kinases and phosphatases include enzymes, neurotransmitter receptors, ion channels, and structural proteins, activating or inhibiting through phosphorylation, the target enzymes or ion channels. The increased cAMP production in response to the activation of $\beta$-adrenergic receptors affects several enzymes that are involved in glycogen metabolism, adipocytes, and muscle cells. The result consists of a coordinated response in which the energy stored as glycogen and fat becomes available as glucose, acting as a supply for muscle contraction (15).

cAMP, a second messenger, and its effector, protein kinase A (PKA), are key regulators of practically all cellular functions, such as cell growth and cell differentiation, and proliferation, and they mediate the effects of several hormones and neurotransmitters via GPCRs. This pathway is one of the major participants in the regulation of growth, proliferation, and hormonal secretion in adrenocortical cells $(16,17)$.

Once two cAMP molecules bind to each $\mathrm{R}$ subunit, the $\mathrm{C}$ subunits are released from the holoenzyme and can phosphorylate their targets, which are localized in the cytosol and in the nucleus. In adrenocortical cells, there is stimulation of glucocorticoid synthesis as well as transcriptional induction of steroidogenic enzymes and activation genes that are involved in cell replication $(15,18)$.
The majority of benign lesions of the adrenal cortex that lead to cortisol overproduction are linked to abnormalities of the cAMP pathway. Genetic defects in the cAMP/PKA that maintain pathway activation have been associated with adrenal disorders as follows:

(1) Ectopic expression of G protein-coupled receptors $(19,20)$.

(2) Somatic activating mutations in the gene coding for the $G \alpha_{s}$ protein $(G N A S)(6,10,21)$.

(3) Somatic activating mutations in the corticotropin receptor gene, $\operatorname{MC} 2 R(22,23)$.

(4) Germline and/or somatic inactivating mutations in the gene coding for the RI $\alpha$ subunit of PKA (PRKAR1A) $(13,14,18)$.

(5) Inactivating germline mutations in the genes coding two phosphodiesterases (PDE8 and PDE11A) $(24,25)$.

(6) Activating germline mutations in the gene coding for the $\mathrm{C} \alpha$ subunit of PKA (PRKACA) (26).

(7) Somatic mutations in PRKACA, which encodes the catalytic subunit of cyclic AMP-dependent protein kinase (27).

(8) Germline and somatic inactivating mutations of ARMC5 $(28,29)$.

Nevertheless, because these molecular events are not able to explain all cases of adrenocortical disorders, part of the molecular pathogenesis of the tumors causing Cushing's syndrome remains a challenge to scientific researchers.

\section{gsp Mutations in Adrenal Cortical Tumors}

Somatic mutations of genes encoding components of the cAMP/ PKA pathway (GNAS, PRKAR1A, PDE8B) and $\beta$-catenin (CTNNB1) have been reported in a small subset of adrenocortical tumors that produce cortisol $(27,30)$.

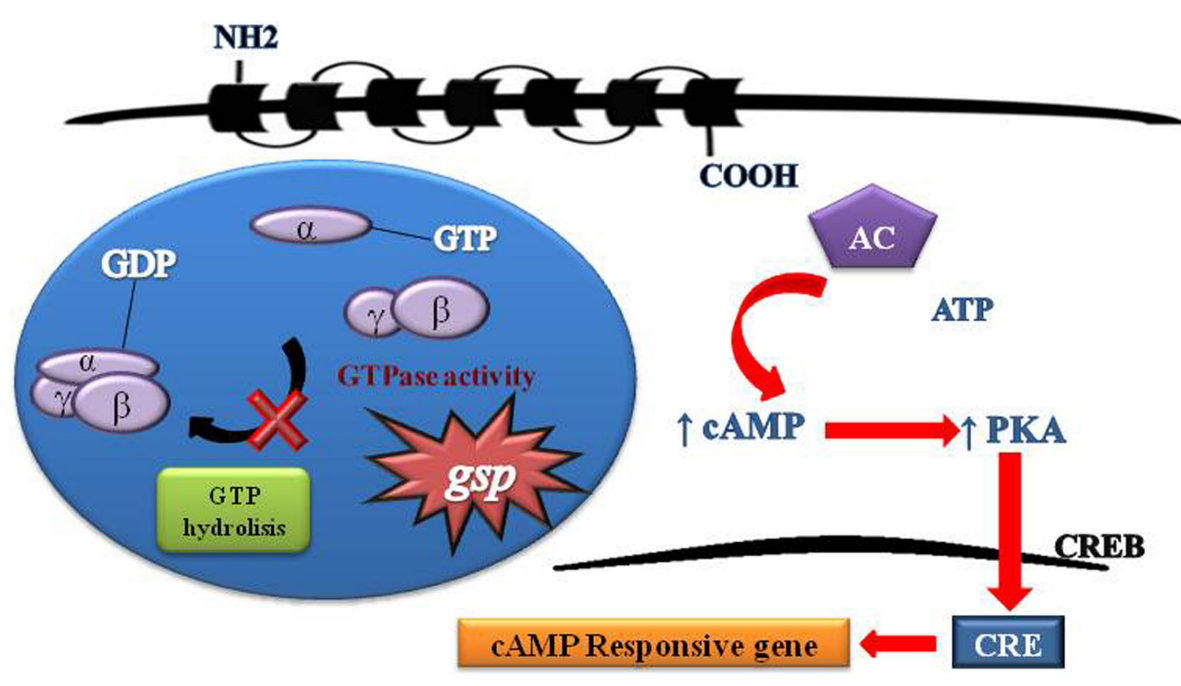

FIGURE 2 | Schematic representation of G protein activation and signaling. Heterotrimeric G proteins are composed of three distinct subunits alpha, beta, and gamma. Activity G protein depends on the alpha subunit. The alpha subunit contains high-affinity binding sites for guanine nucleotides (GDP) and has intrinsic GTPase activity. The GDP-bound form binds tightly to beta and gamma units in its inactive state. The GTP-bound form dissociates from beta and gamma units and serves as a regulator of effectors proteins. The receptor molecules cause the activation of G proteins by facilitating the exchange of GTP for GDP on the alpha subunit. The duration of subunit separation is timed by the rate of alpha subunit-mediated hydrolysis of GTP. The gsp mutations Arg201Cys and Gln227Arg at exons 8 and 9, respectively, of GNAS causing a constitutive signal of cAMP pathway. 
The first report of the involvement of $g s p$ mutations in adrenal tumors was by Lyons et al. In this study, the group tested the gene that encodes the alpha chain of Gi2, and the authors detected mutations that replaced arginine-179 with either cysteine or histidine in 3 of 11 tumors of the adrenal cortex and 3 of 10 endocrine tumors of the ovary (31).

Yoshimoto et al. systemically screened Gs alpha mutations in 197 human endocrine tumors. They included pituitary, thyroid, parathyroid, endocrine pancreas, and (cortex and medulla) adrenal tumors. They identified a unique, 29-year-old female patient with primary aldosteronism associated with a somatic $g s p$ mutation in an aldosterone-producing adrenocortical adenoma. The authors commented that when the renin-aldosterone system is suppressed, aldosterone-producing adrenal adenomas become more sensitive to corticotropin stimulation. In this way, corticotropin is transmitted via Gs alpha-mediated cyclic AMP production. The study hypothesized that the gsp mutations may constitutively stimulate aldosterone synthesis in the glomerulosa zone, transmitting a constitutive signal via Gs-mediated cyclic AMP production, which would play an important role in the tumorigenesis of the aldosterone-secreting adenoma (3).

In 2000, Bugalho et al. described the presence of a mutation at codon 201 (CGT to TGT) in a patient with Cushing's syndrome due to a functioning adrenal adenoma (32). In 2004, Dall'Asta et al. also identified $g s p$ mutations in one patient with $\mathrm{ACTH}$-independent Cushing's syndrome. The presence of the $g s p$ mutation seemed to alter the cortisol responses to agents via Gs protein-coupled receptors, whereas these responses are absent in other cases of adenoma-producing Cushing's syndrome without gsp mutations (33).

Moreover, Libé and Bertherat investigated the presence of genetic alterations on a series of $10 \mathrm{ACTH}$-independent Cushing's syndrome cases due to adrenocortical cortisol-secreting adenomas. The gsp mutation was identified in only one case, demonstrating that this abnormality is a rare cause of adrenocortical tumors. These findings suggest that different mechanisms are probably involved in adrenal tumorigenesis in primarily benign disorders (34).

A study conducted by Almeida et al. using the whole-genome expression profile (WGEP) of PRKAR1A and GNAS-mutant analysis revealed that not all cAMP activation is the same. Adrenal lesions harboring PRKAR1A or GNAS mutations share downstream activation of specific oncogenic signals (such as MAPK and cell cycle genes), but they differ substantially in their effects on others. These results support the hypothesis that several pathways can activate cAMP (13).

In 2013, Sidhu et al. described, for the first time, the presence of the p.R201C, a GNAS activating mutation in a malignant pediatric adrenocortical tumor. The malignant features described were as follows: areas of necrosis, microcytic degeneration, and both venous and capsular microinvasion. The tumor tissue also presented with abnormal allele-specific hypomethylation of the KCNQ1OT1 gene involved in Beckwith-Wiedemann syndrome. Somatic mutations in these genes may constitutively activate the cAMP-protein kinase cascade, leading to cellular proliferation, which may then result in genomic instability and epigenetic alterations that give rise to ACTs and malignancy. This study suggested, for the first time, that activation of the cAMP-PKA cascade alone may not be sufficient to cause malignant transformation in the adrenal cortex without resulting in secondary events (35).

Recently, somatic mutations of PRKACA (encoding the catalytic subunit of PKA) have been identified in more than one-third of the patients with Cushing's syndrome from sporadic adrenocortical adenomas; however, the molecular pathogenesis of the majority of sporadic adrenocortical tumors remains unclear $(18,27,36)$.

In summary, apart from the known somatic mutations described in the literature, no other recurrent mutation by itself can explain the mechanism of tumor formation and hormone hypersecretion.

\section{gsp Mutations in Primary Macronodular Adrenal Hyperplasia}

Over the last two decades, different studies have supported that multiple molecular mechanisms may be involved in the pathogenesis of PMAH $(7,12-14,37)$. Several pathways were studied and analyzed for gene alterations, suggesting that there may be a heterogeneous group of diseases with a common presentation, ranging from subclinical hypercortisolism to overt Cushing's syndrome.

Bilateral adrenal hyperplasia may be part of MAS that is associated with hypercortisolism, especially in young children during the first years of age. The adrenal nodules of these patients carried the $g s p$ mutation and adrenal cortical cells increased the levels of cAMP $(6,8)$.

In 2003, Fragoso et al. identified two distinct gsp somatic mutations affecting arginine residues in codon 201 of GNAS in a few patients with PMAH without any features or manifestations of MAS (2).

Subsequently, Hsiao et al. also reported the presence of $g s p$ somatic mutation in one additional patient with PMAH (4). On the other hand, an additional study failed to observe $g s p$ mutations in PMAH (37). Technical variations in the methodologies employed for the investigation of $g s p$ mutations could explain the discrepancy in these published findings.

Almeida et al. described the analyzed the WGEP of primary pigmented nodular adrenocortical disease (PPNAD) patients associated with gsp mutations. The data indicated that cAMP activation in adrenal lesions harboring $g s p$ mutations share the downstream activation of some oncogenic signals but differ significantly in their effects on others (13).

Considering the great variation of MAS, these cases might characterize late $g s p$ somatic mutations considering that similar mutations have been described outside the context of MAS (e.g., acromegaly, thyroid cancer, and ovarian-testicular neoplasms) (7).

Based on strong previous evidence implying that increased cAMP signaling is sufficient for cell proliferation and cortisol production, we posit that although these somatic activating mutations in GNAS are a rare molecular event, they are probably sufficient to induce the development of macronodule hyperplasia and variable cortisol secretion $(12,38,39)$.

Primary macronodular adrenocortical hyperplasia is a heterogeneous disorder that could be associated with genetic defects in 
both germline and somatic levels. The presence of somatic gsp mutations was detected in rare cases with PMAH without MAS features. The role of $g s p$ mutations in the development of this adrenal disorder remains partially unclear (2).

Recent studies have now indicated that PMAH is more frequently genetically determined than previously believed $(28,29)$. Germline mutations of ARMC5 in 50\% of patients with apparently sporadic PMAH, and also in a large family with genetically transmitted PMAH. The ARMC5 has no apparent link to the cAMP pathway, but its inactivation decreases the expression of both MC2R and various steroidogenic enzymes (19).

\section{Activation of Cyclic AMP Signaling in Lesions of the Adrenal Cortex due to Somatic GNAS Mutations}

Aberrations in CAMP/PKA signaling are essential to the pathogenesis of benign cortisol-producing lesions of the adrenal cortex (40).

An important study by Almeida and coauthors analyzed the WGEP of adrenal lesions harboring somatic GNAS mutations in the normal adrenal pool and tissue with somatic PRKAR1A genes. They included three microdissected samples from adrenal lesions that were all caused by the same somatic GNAS mutation (p.R201H) as follows: a cortisol-producing adenoma from patients with PMAH and Cushing's syndrome and hyperplasia from patients with MAS and Cushing's syndrome. The results of this study showed that the MAPK and p53 signaling pathways were highly overexpressed in all lesions compared with normal tissues. GNAS-mutant tissues were significantly enriched for extracellular matrix receptor interaction and focal adhesion pathways compared with PRKAR1A mutants. In addition, NFKB, NFKBIA, and TNFRSF1A were overexpressed in GNAS-mutant adrenal tissue (13).

$N F K B$ is a transcription activator nuclear factor kappa light-chain enhancer of activated B cells, a complex protein that controls DNA transcription, cytokine production, and cell survival. The nuclear factor kappa-beta controls the expression of various genes that are involved in cancer-related processes, including immune and inflammatory responses; cell adhesion, proliferation, differentiation, and apoptosis; and angiogenesis (13).

TNFRSF1A is a tumor necrosis factor receptor member of the superfamily $1 \mathrm{~A}$ and the protein encoded by this gene is a member of the TNF-receptor superfamily. This protein is one of the major receptors for tumor necrosis factor-alpha. This receptor can activate NF-kappa-beta and mediate apoptosis, and it functions as a regulator of inflammation (13).

The study of adrenal lesions harboring PRKAR1A or GNAS mutations, conducted by Almeida et al. suggested that cAMP signaling inhibitors could be used as molecularly designed therapies for subclinical CS in the context of bilateral adrenal hyperplasia (13).

Despite the importance of the cAMP pathway, these molecular events are a rare cause of adrenocortical tumors and adrenal hyperplasia, showing that several other genes should be involved in the cAMP pathway as long as other genes are involved in adrenal tumorigenesis and hyperplastic development.

\section{NEW INSIGHTS}

This review aimed to provide a summary of the main studies on the role of cAMP and gsp mutations on the development of adrenocortical tumors and adrenal hyperplasia. Throughout this review, we showed that $g s p$ mutations are a rare cause of adrenal disorders and involvement of $g s p$ mutations in increasing the cAMP levels is not always detected.

The molecular pathogenesis of cortisol-producing adrenal adenomas and adrenal hyperplasia is not well understood.

Somatic mutations in the gene encoding beta-catenin (CTNNB1) have primarily been found in non-secreting adrenocortical adenomas, and there is some evidence that increased endocrine activity may be linked to aberrant cAMP signaling.

Tumor suppressor genes point mutations (such as CTNNB1) and alterations in the cortisol producing ( $A R M C 5$ and $P K C$ mutations) could lead to alterations in cAMP pathway.

Mutations in the genes PDE11A, PDE8B, and PRKAR1A have also been identified in patients with adrenal disorders related to cortisol production (14).

Nevertheless, lesions of the adrenal gland that are associated with adrenal Cushing syndrome, independent of their GNAS, PRKAR1A, PDE11A, and PDE8B mutations, have functional abnormalities in CAMP signaling. It is hypothesized that epigenetic events or additional genetic defects of the regulatory molecules in this pathway exist and have yet to be identified (41).

\section{CONCLUSION}

The genetic analyses of the molecular pathogenesis of sporadic cortisol-secreting adrenocortical adenomas confirm the key role of the cAMP/PKA-signaling pathway in stimulating both the function and proliferation of adrenocortical cells. They provide insights into the development of adrenal hormonal autonomy and may provide the basis for novel advances in the diagnosis and therapy of adrenal Cushing's syndrome.

In conclusion, this review demonstrates that not all increased cAMP/PKA signaling has the same effect on adrenocortical tumor formation. The role of non-PKA-dependent functions of cAMP in the adrenal cortex has not been adequately investigated.

Based on strong previous evidence implying that increased cAMP signaling is sufficient for cell proliferation and cortisol production (38), we surmise that although really rare, these $g s p$ mutations are probably sufficient for macronodule formation and the hypercortisolism status.

\section{AUTHOR CONTRIBUTIONS}

MCBVF, IQW, IPC, BMPM: All authors contributed equally for the article. 


\section{REFERENCES}

1. Dumitrescu CE, Collins MT. McCune-Albright syndrome. Orphanet J Rare Dis (2008) 3:12. doi:10.1186/1750-1172-3-12

2. Fragoso MC, DomeniceS, Latronico AC, Martin RM, Pereira MA, Zerbini MC, et al. Cushing's syndrome secondary to adrenocorticotropin-independent macronodular adrenocortical hyperplasia due to activating mutations of GNAS1 gene. J Clin Endocrinol Metab (2003) 88(5):2147-51. doi:10.1210/ jc.2002-021362

3. Yoshimoto K, Iwahana H, Fukuda A, Sano T, Itakura M. Rare mutations of the Gs alpha subunit gene in human endocrine tumors. Mutation detection by polymerase chain reaction-primer-introduced restriction analysis. Cancer (1993) 72(4):1386-93. doi:10.1002/1097-0142(19930815)72:4<1386::AIDCNCR2820720439>3.0.CO;2-J

4. Hsiao HP, Kirschner LS, Bourdeau I, Keil MF, Boikos SA, Verma S, et al. Clinical and genetic heterogeneity, overlap with other tumor syndromes, and atypical glucocorticoid hormone secretion in adrenocorticotropin-independent macronodular adrenal hyperplasia compared with other adrenocortical tumors. J Clin Endocrinol Metab (2009) 94(8):2930-7. doi:10.1210/ jc. 2009-0516

5. Hamm HE. The many faces of G protein signaling. J Biol Chem (1998) 273(2):669-72. doi:10.1074/jbc.273.2.669

6. Weinstein LS, Liu J, Sakamoto A, Xie T, Chen M. Minireview: GNAS: normal and abnormal functions. Endocrinology (2004) 145(12):5459-64. doi:10.1210/ en.2004-0865

7. Antonini SR, Fragoso MC, Lacroix A. [Clinical and molecular aspects of the ACTH-independent bilateral macronodular adrenal hyperplasia]. Arq Bras Endocrinol Metabol (2004) 48(5):620-36. doi:10.1590/S000427302004000500006

8. Brown RJ, Kelly MH, Collins MT. Cushing syndrome in the McCune-Albright syndrome. JClin Endocrinol Metab (2010) 95(4):1508-15. doi:10.1210/ jc. 2009-2321

9. Happle R. The McCune-Albright syndrome: a lethal gene surviving by mosaicism. Clin Genet (1986) 29(4):321-4. doi:10.1111/j.1399-0004.1986. tb01261.x

10. Landis CA, Masters SB, Spada A, Pace AM, Bourne HR, Vallar L. GTPase inhibiting mutations activate the alpha chain of Gs and stimulate adenylyl cyclase in human pituitary tumours. Nature (1989) 340(6236):692-6. doi:10.1038/340692a0

11. Lacroix A, Bourdeau I, Lampron A, Mazzuco TL, Tremblay J, Hamet P. Aberrant G-protein coupled receptor expression in relation to adrenocortical overfunction. Clin Endocrinol (2010) 73(1):1-15. doi:10.1111/j.1365-2265.2009.03689.x

12. de Joussineau C, Sahut-Barnola I, Levy I, Saloustros E, Val P, Stratakis CA, et al. The cAMP pathway and the control of adrenocortical development and growth. Mol Cell Endocrinol (2012) 351(1):28-36. doi:10.1016/j. mce.2011.10.006

13. Almeida MQ, Azevedo MF, Xekouki P, Bimpaki EI, Horvath A, Collins MT, et al. Activation of cyclic AMP signaling leads to different pathway alterations in lesions of the adrenal cortex caused by germline PRKAR1A defects versus those due to somatic GNAS mutations. JClin Endocrinol Metab (2012) 97(4):E687-93. doi:10.1210/jc.2011-3000

14. Bimpaki EI, Nesterova M, Stratakis CA. Abnormalities of cAMP signaling are present in adrenocortical lesions associated with ACTH-independent Cushing syndrome despite the absence of mutations in known genes. Eur J Endocrinol (2009) 161(1):153-61. doi:10.1530/EJE-09-0027

15. Almeida MQ, Stratakis CA. How does cAMP/protein kinase A signaling lead to tumors in the adrenal cortex and other tissues? Mol Cell Endocrinol (2011) 336(1-2):162-8. doi:10.1016/j.mce.2010.11.018

16. Bertherat J, Groussin L, Sandrini F, Matyakhina L, Bei T, Stergiopoulos S, et al. Molecular and functional analysis of PRKAR1A and its locus (17q22-24) in sporadic adrenocortical tumors: $17 \mathrm{q}$ losses, somatic mutations, and protein kinase A expression and activity. Cancer Res (2003) 63(17):5308-19.

17. Lefebvre H, Duparc C, Prévost G, Bertherat J, Louiset E. Cell-to-cell communication in bilateral macronodular adrenal hyperplasia causing hypercortisolism. Front Endocrinol (2015) 6:34. doi:10.3389/fendo.2015.00034

18. Bourdeau I, Matyakhina L, Stergiopoulos SG, Sandrini F, Boikos S, Stratakis CA. 17q22-24 chromosomal losses and alterations of protein kinase a subunit expression and activity in adrenocorticotropin-independent macronodular adrenal hyperplasia. JClin Endocrinol Metab (2006) 91(9):3626-32. doi:10.1210/jc.2005-2608

19. Assie G, Louiset E, Sturm N, René-Corail F, Groussin L, Bertherat J, et al. Systematic analysis of $\mathrm{G}$ protein-coupled receptor gene expression in adrenocorticotropin-independent macronodular adrenocortical hyperplasia identifies novel targets for pharmacological control of adrenal Cushing's syndrome. J Clin Endocrinol Metab (2010) 95(10):E253-62. doi:10.1210/ jc.2009-2281

20. Lacroix A, Tremblay J, Rousseau G, Bouvier M, Hamet P. Propranolol therapy for ectopic beta-adrenergic receptors in adrenal Cushing's syndrome. N Engl J Med (1997) 337(20):1429-34. doi:10.1056/NEJM199711133372004

21. Levine MA, Jap TS, Mauseth RS, Downs RW, Spiegel AM. Activity of the stimulatory guanine nucleotide-binding protein is reduced in erythrocytes from patients with pseudohypoparathyroidism and pseudopseudohypoparathyroidism: biochemical, endocrine, and genetic analysis of Albright's hereditary osteodystrophy in six kindreds. J Clin Endocrinol Metab (1986) 62(3):497-502.

22. Almeida MQ, Kaupert LC, Brito LP, Lerario AM, Mariani BM, Ribeiro M, et al. Increased expression of ACTH (MC2R) and androgen (AR) receptors in giant bilateral myelolipomas from patients with congenital adrenal hyperplasia. BMC Endocr Disord (2014) 14:42. doi:10.1186/1472-6823-14-42

23. Swords FM, Noon LA, King PJ, Clark AJ. Constitutive activation of the human ACTH receptor resulting from a synergistic interaction between two naturally occurring missense mutations in the MC2R gene. Mol Cell Endocrinol (2004) 213(2):149-54. doi:10.1016/j.mce.2003.10.052

24. Horvath A, Boikos S, Giatzakis C, Robinson-White A, Groussin L, Griffin KJ, et al. A genome-wide scan identifies mutations in the gene encoding phosphodiesterase 11A4 (PDE11A) in individuals with adrenocortical hyperplasia. Nat Genet (2006) 38(7):794-800. doi:10.1038/ng1809

25. Horvath A, Mericq V, Stratakis CA. Mutation in PDE8B, a cyclic AMP-specific phosphodiesterase in adrenal hyperplasia. N Engl J Med (2008) 358(7):750-2. doi:10.1056/NEJMc0706182

26. Calebiro D, Hannawacker A, Lyga S, Bathon K, Zabel U, Ronchi C, et al. PKA catalytic subunit mutations in adrenocortical Cushing's adenoma impair association with the regulatory subunit. Nat Commun (2014) 5:5680. doi:10.1038/ ncomms 6680

27. Beuschlein F, Fassnacht M, Assié G, Calebiro D, Stratakis CA, Osswald A, et al. Constitutive activation of PKA catalytic subunit in adrenal Cushing's syndrome. N Engl J Med (2014) 370(11):1019-28. doi:10.1056/NEJMoa1310359

28. Assié G, Libé R, Espiard S, Rizk-Rabin M, Guimier A, Luscap W, et al. ARMC5 mutations in macronodular adrenal hyperplasia with Cushing's syndrome. N Engl J Med (2013) 369(22):2105-14. doi:10.1056/NEJMoa1304603

29. Alencar GA, Lerario AM, Nishi MY, Mariani BM, Almeida MQ, Tremblay J, et al. ARMC5 mutations are a frequent cause of primary macronodular adrenal Hyperplasia. J Clin Endocrinol Metab (2014) 99(8):E1501-9. doi:10.1210/ jc.2013-4237

30. Durand J, Lampron A, Mazzuco TL, Chapman A, Bourdeau I. Characterization of differential gene expression in adrenocortical tumors harboring beta-catenin (CTNNB1) mutations. J Clin Endocrinol Metab (2011) 96(7):E1206-11. doi:10.1210/jc.2010-2143

31. Lyons J, Landis CA, Harsh G, Vallar L, Grünewald K, Feichtinger H, et al. Two G protein oncogenes in human endocrine tumors. Science (1990) 249(4969):655-9. doi:10.1126/science.2116665

32. Bugalho MJ, Li X, Rao CV, Soares J, Sobrinho LG. Presence of a Gs alpha mutation in an adrenal tumor expressing LH/hCG receptors and clinically associated with Cushing's syndrome. Gynecol Endocrinol (2000) 14(1):50-4. doi:10.3109/09513590009167660

33. Dall'Asta C, Ballarè E, Mantovani G, Ambrosi B, Spada A, Barbetta L, et al. Assessing the presence of abnormal regulation of cortisol secretion by membrane hormone receptors: in vivo and in vitro studies in patients with functioning and non-functioning adrenal adenoma. Horm Metab Res (2004) 36(8):578-83. doi:10.1055/s-2004-825797

34. Libé R, Bertherat J. Molecular genetics of adrenocortical tumours, from familial to sporadic diseases. Eur J Endocrinol (2005) 153(4):477-87. doi:10.1530/ eje.1.02004

35. Sidhu A, Debelenko L, Misra VK. Infantile adrenocortical tumor with an activating GNAS1 mutation. J Clin Endocrinol Metab (2013) 98(1):E115-8. doi:10.1210/jc.2012-2933 
36. Libé R, Mantovani G, Bondioni S, Lania AG, Pedroni C, Beck-Peccoz P, et al. Mutational analysis of PRKAR1A and Gs(alpha) in sporadic adrenocortical tumors. Exp Clin Endocrinol Diabetes (2005) 113(5):248-51. doi:10.1055/s-2005-837651

37. Christopoulos S, Bourdeau I, Lacroix A. Clinical and subclinical ACTHindependent macronodular adrenal hyperplasia and aberrant hormone receptors. Horm Res (2005) 64(3):119-31. doi:10.1159/000088818

38. Lania AG, Mantovani G, Spada A. Mechanisms of disease: mutations of $\mathrm{G}$ proteins and G-protein-coupled receptors in endocrine diseases. Nat Clin Pract Endocrinol Metab (2006) 2(12):681-93. doi:10.1038/ ncpendmet0324

39. Meoli E, Bossis I, Cazabat L, Mavrakis M, Horvath A, Stergiopoulos S, et al. Protein kinase A effects of an expressed PRKAR1A mutation associated with aggressive tumors. Cancer Res (2008) 68(9):3133-41. doi:10.1158/0008-5472. CAN-08-0064

40. Boston BA, Mandel S, LaFranchi S, Bliziotes M. Activating mutation in the stimulatory guanine nucleotide-binding protein in an infant with Cushing's syndrome and nodular adrenal hyperplasia. J Clin Endocrinol Metab (1994) 79(3):890-3. doi:10.1210/jcem.79.3.8077378

41. Fragoso MC, Alencar GA, Lerario AM, Bourdeau I, Almeida MQ, Mendonca BB, et al. Genetics of primary macronodular adrenal hyperplasia. J Endocrinol (2015) 224(1):R31-43. doi:10.1530/JOE-14-0568

Conflict of Interest Statement: The authors declare that the research was conducted in the absence of any commercial or financial relationships that could be construed as a potential conflict of interest.

Copyright (c) 2016 Villares Fragoso, Wanichi, Cavalcante and Mariani. This is an open-access article distributed under the terms of the Creative Commons Attribution License (CC BY). The use, distribution or reproduction in other forums is permitted, provided the original author(s) or licensor are credited and that the original publication in this journal is cited, in accordance with accepted academic practice. No use, distribution or reproduction is permitted which does not comply with these terms. 